\title{
SYNTHESIS, CHARACTERIZATION AND APPLICATION OF CARBOXYMETHYL POTATO STARCH OBTAINED FROM WASTE
}

\author{
SUMEYYE AKARSU* and MUSTAFA DOLAZ ${ }^{* * * * * *}$ \\ *Department of Food Engineering, Faculty of Engineering, Sakarya University, \\ Sakarya 54187, Turkey \\ *** Department of Environmental Engineering, Faculty of Engineering and Architecture, Kahramanmaras \\ Sutcu Imam University, Kahramanmaras 46100, Turkey \\ ${ }^{* * * *}$ Research and Development Centre for University-Industry-Public Relations, Kahramanmaras Sutcu \\ Imam University, 46100 Kahramanmaras, Turkey \\ \Corresponding author: Mustafa Dolaz,mdolaz@ksu.edu.tr,dolazmustafa@gmail.com
}

Received June 7, 2018

\begin{abstract}
Waste potato starch (WPS) was obtained from the food industry during slicing, peeling and washing potatoes in the process of producing potato chips. After it was purified with $\mathrm{H}_{2} \mathrm{O}_{2}$ and $\mathrm{NaOH}$ at the desired temperature, carboxymethyl potato starch (CMPS), with the DS in the range from 0.04 to 1.24, was synthesized in isopropanol (IPA) and $\mathrm{NaOH}$ solution by adding monochloroacetic acid (MCA). Considering all the studied conditions, the best results were achieved when IPA was used as solvent at $45{ }^{\circ} \mathrm{C}$ for $180 \mathrm{~min}$ and at a $\mathrm{NaOH} / \mathrm{MCA}$ molar ratio of 2.2:1. CMPS-2, obtained under these conditions, reached a viscosity of $14200 \mathrm{mPa}$ 's (for $2 \%$ CMPS in water at $1 \mathrm{rpm}$ ) for the highest DS. The samples were investigated by determining their DS and by SEM, FTIR, XRD, NMR and thermal analyses. Moreover, the viscosity of the CMPS aqueous solutions was measured. $100 \%$ cotton yarns with different numbers (10/1, 20/1 and 30/1 Ne) were sized with CMPS-29, CMPS-27, CMPS-25 and CMPS-22, and then their tensile strength and elongation at break were measured. The tensile strength of the sized samples increased by $87.65 \%$, compared with that sized with WPS. Also, CMPS with DS 0.04 exhibited considerably better sizing properties, compared to WPS.
\end{abstract}

Keywords: waste, carboxymethyl potato starch, FT-IR, XRD, sizing

\section{INTRODUCTION}

Conversion of industrial food waste materials into useful products would facilitate a greener approach to manufacturing. Waste potato starch (WPS) is a by-product in the production of potato chips. It is a cheap, biodegradable, non-toxic and renewable natural polymer, available in great quantities on a global level. ${ }^{1}$

Brittleness and retrogradation are issues related to starch films after e.g. thermoplasticization. Starch has $\mathrm{OH}$ groups that can take part in many types of reactions characteristic of this functional group (e.g. etherification, esterification, oxidation, acylation). ${ }^{2}$ In order to utilize starch in industrial applications, it must be converted into its derivatives. Hence, chemical modification proposes an interesting alternative to achieve new materials with biodegradation properties. Chemical modification of starch includes the reaction of the hydroxyl groups on the anhydroglucose units (AGU), which have been used to generate starch derivatives based on carboxymethylation, ${ }^{3}$ crosslinking, ${ }^{4,5}$ oxidation, ${ }^{6}$ hydroxypropylation ${ }^{7,8}$ and grafting. ${ }^{9}$ Among these derivatives, carboxymethyl starch (CMS) has attracted a lot of attention in industry. ${ }^{10}$ In general, CMS is synthesized under alkali conditions by the reaction of MCA and starch. In the alkalization step, the hydroxyl groups on starch (St-OH) molecules are changed to the more reactive alkoxide form (Eqs. 1, 2):

$$
\begin{aligned}
& \mathrm{St}-\mathrm{OH}+\mathrm{NaOH} \leftrightarrow \mathrm{St}-\mathrm{O}^{-} \mathrm{Na}^{+}+\mathrm{H}_{2} \mathrm{O} \\
& \mathrm{St}-\mathrm{O}^{-} \mathrm{Na}+
\end{aligned}
$$

Nevertheless, a side reaction takes place, producing sodium glycolate, with MCA and sodium hydroxide according to the following equation (Eq. 3): 
$\mathrm{NaOH}+\mathrm{Cl}-\mathrm{CH}_{2} \mathrm{COONa} \rightarrow \mathrm{HO}-\mathrm{CH}_{2} \mathrm{COONa}+\mathrm{NaCl}$ (3)

Sodium carboxymethyl starch is an anionic, water-soluble, man-modified polysaccharide. Purified CMS is a white- to cream-colored, odorless powder. Some papers have reported the synthesis of CMS from various sources: cassava starch, ${ }^{11-13}$ amaranth, ${ }^{14}$ high-amylose corn, ${ }^{15}$ potato, ${ }^{16-22}$ wheat, ${ }^{23}$ rice, ${ }^{24,25}$ mungbean, ${ }^{26}$ Chinese yam and Cassia tora gum, ${ }^{27}$ kudzu root starch, ${ }^{28}$ wastes from corn starch and potato flour, ${ }^{29}$ sorghum, ${ }^{30}$ arrowroot starch $^{31}$ and water yam (Dioscorea alata) starch. $^{32}$

CMS is the most widely used starch with applications in pharmaceutical applications, ${ }^{17,33,34}$ textile, ${ }^{35-38}$ environmental, ${ }^{39,40}$ paper and food industries. ${ }^{41,42}$

In this study, we used waste potato starch (WPS) from a chips factory to obtain carboxymethyl potato starch (CMPS). We investigated the size and shape of CMPS particles, the viscosity of CMPS aqueous solutions, as well as the degree of substitution, the crystalline characteristics and the thermal stability properties of CMPSs. The characterized CMPSs were then used as sizing agent in textile processing. This work aims to convert waste potato starch into a useful sizing material.

\section{EXPERIMENTAL}

\section{Materials}

Following the synthesis process, the viscosity of each CMPS obtained was measured by a BrookfieldPrime DV-I digital viscometer (ASTM D2364, USA). Infrared spectra were obtained on a Perkin Elmer Spectrum 100 FT-IR, using $\mathrm{KBr}$ discs $\left(4000-400 \mathrm{~cm}^{-}\right.$ ${ }^{1}$ ). The morphological structures of WPS and CMPSs were investigated by a Jeal/Neoscope JCM-5000 SEM. ${ }^{13} \mathrm{C}$-NMR spectroscopy (Bruker Superconducting FTNMR Spectrometer Avance TM $300 \mathrm{MHz}$ WB) and ${ }^{1} \mathrm{H}-\mathrm{NMR}$ spectroscopy (Bruker Biospin $300 \mathrm{MHz}$ NMR Spectrophotometer) were used. For this, the required amount of CMPS powder was dispersed in $\mathrm{D}_{2} \mathrm{O}$ in a tube at $25{ }^{\circ} \mathrm{C}$ under vigorous stirring. Measurements were carried out at room temperature. The thermal studies of WPS and CMPS were performed on a Perkin Elmer STA 6000 Simultaneous Thermal Analyzer under nitrogen atmosphere, at a heating rate of $10{ }^{\circ} \mathrm{C} / \mathrm{min}$. The XRD of each sample was conducted using a Philips X'Pert PRO MPD X-ray Diffraction System PW3040/60. Strength tests were performed on a Zwick Roell Z5.0 Universal Testing Machine according to TS EN ISO 2062:2009.

WPS was supplied by Seydisehir-Beysehir Torku Potato Chips Factory, Konya, Turkey. Cotton yarns $(10 / 1 \mathrm{Ne}, 20 / 1 \mathrm{Ne}$ and 30/1 Ne 100\% cotton yarn) were supplied by KIPAŞ Holding, Kahramanmaras,
Turkey. Monochloroacetic acid (MCA), isopropanol (IPA), sodium hydroxide $(\mathrm{NaOH})$, hydrogen peroxide $\left(\mathrm{H}_{2} \mathrm{O}_{2}\right)$, glacial acetic acid $\left(\mathrm{CH}_{3} \mathrm{COOH}\right)$, copper sulfate penthahydrate $\left(\mathrm{CuSO}_{4} \cdot 5 \mathrm{H}_{2} \mathrm{O}\right)$, ethanol $\left(\mathrm{C}_{2} \mathrm{H}_{5} \mathrm{OH}\right)$, methanol $\left(\mathrm{CH}_{3} \mathrm{OH}\right)$, ammonium chloride $\left(\mathrm{NH}_{4} \mathrm{Cl}\right)$, hydrochloric acid $(\mathrm{HCl})$, murexide and ethylenediaminetetraacetic acid disodium salt dihydrate $\left(\mathrm{Na}_{2}\right.$ EDTA $\left.2 \mathrm{H}_{2} \mathrm{O}\right)$ were purchased from Merck. All the chemicals were reagent pure grade and were used without further purification.

\section{Preparation of CMPS}

The reactions were performed in a glass batch reactor equipped with mechanical stirrer and thermocouple. The first process was the purification of the starches. WPS $(50 \mathrm{~g})$ and $3 \mathrm{~g}$ of $\mathrm{NaOH}$ in $15 \mathrm{~mL}$ water were suspended in a certain volume of IPA and heated to $45^{\circ} \mathrm{C}$. Then, hydrogen peroxide $(5 \mathrm{~mL}, 30 \%$ $\mathrm{w} / \mathrm{w})$ was added and the mixture was stirred for 90 min. After cooling down to room temperature, the sample was neutralized with glacial acetic acid, washed with distilled water three times, and dried at 40 ${ }^{\circ} \mathrm{C}$ in vacuum. In the second step, the carboxymethylation of WPS was realized according to a reported method. ${ }^{43}$ The sodium salt solution of monochloroacetic acid was dissolved in IPA in the glass reactor and an aqueous solution of sodium hydroxide was added. After $15 \mathrm{~min}, 10 \mathrm{~g}$ of starch (ca. 15 wt\% moisture) and $\mathrm{NaOH}$ microgranules were slowly introduced (Table 1). The temperature of the reaction mixture was raised to $45{ }^{\circ} \mathrm{C}$ and allowed to react for $3 \mathrm{~h}$ under constant stirring. Then, the reaction mixture was cooled and neutralized with glacial acetic acid. The product was washed three times with $80 \%$ $(\mathrm{v} / \mathrm{v})$ methanol and pure methanol, filtered and dried in an oven at $40{ }^{\circ} \mathrm{C}$ in a vacuum (Fig. 1).

\section{Determination of DS}

The degree of substitution by carboxymethyl groups was determined by quantifying the amount of carboxymethyl groups on the CMPSs (reported in Table 1) by using a previously described method. ${ }^{44}$ Briefly, carboxymethyl potato starch was moisturized by $1 \mathrm{~mL}$ of ethanol and dissolved in $50 \mathrm{~mL}$ of distilled water, followed by adding $20 \mathrm{~mL}$ of $0.187 \mathrm{M} \mathrm{NH}_{4} \mathrm{Cl}$ buffer and adjusted to neutral $\mathrm{pH}$. The whole mixture was poured into a flask with $50 \mathrm{~mL}$ of $0.039 \mathrm{M}$ in copper sulphate salt $\left(\mathrm{CuSO}_{4} \cdot 5 \mathrm{H}_{2} \mathrm{O}\right)$. After 15 minutes, bidistilled water was added to the slurry and the content was filtered. The filtrate was titrated with 0.05 M EDTA solution, using murexide as an indicator, by an SI Analytics TitroLine 6000 Titrator.

\section{Measurements of viscosity}

An aqueous solution of carboxymethyl potato starch was prepared by adding CMPS to distilled water under stirring with a magnetic stirrer and mixed until homogeneous. After 30 minutes, the viscosity of the samples was measured (Table 2). The viscosity of a 
$2 \%$ water solution of CMPSs was measured in a rotary viscometer (Brookfield Prime DV-I) at $25^{\circ} \mathrm{C}$, varying spindle rotation from 1 up to $100 \mathrm{rpm}$.

\section{Textile sizing}

Pure cotton yarns $(10 / 1,20 / 1$ and $30 / 1 \mathrm{Ne})$ were sized with WPS, CMPS-29 (DS = 0.04), CMPS-27 $(\mathrm{DS}=0.14), \mathrm{CMPS}-25(\mathrm{DS}=0.39)$ and CMPS-22 (DS $=0.65)$. For this process, $5 \mathrm{~g}$ of CMPS samples were dissolved in $50 \mathrm{~mL}$ tap water for 10 minutes under slow stirring. The solution was heated at 90 ${ }^{\circ} \mathrm{C}$ for 30 minutes and the $\mathrm{pH}$ was adjusted to 7.5 8.5. Each yarn intended for sizing was immersed into the solution for 5 minutes and then squeezed out. The sized yarns were then dried for 5 minutes at $90{ }^{\circ} \mathrm{C}$. Before the sized yarns (twenty-five specimens of $25 \mathrm{~cm}$ length) were tested for tensile strength (cN/tex) and tensile elongation (\%), according to TS EN ISO 2062:2009, with a pulling speed of $250 \mathrm{~mm} / \mathrm{min}$ and a preload of $0.5 \mathrm{cN} / \mathrm{tex}$, they were conditioned for 24 hours (Table 3 ).

\section{RESULTS AND DISCUSSION}

Carboxymethyl potato starch with the DS of 0.04-1.24 was synthesized under of a variety of reaction conditions. The molar ratio of $\mathrm{NaOH} / \mathrm{MCA}$ was changed, and simultaneously the MCA/AGU molar ratio was also changed (0.01-3.0). The granular samples were investigated by DS determination, as well as by SEM, FTIR, XRD, NMR and thermal analyses. Moreover, the viscosity of the CMPS aqueous solutions was measured. The results revealed that $\mathrm{NaOH}$ and MCA affected the DS. As the amount of $\mathrm{NaOH}$ increased, the DS value also increased. However, the further increase in the amount of $\mathrm{NaOH}$ had a negative impact on the DS values. On the other hand, MCA has a positive effect on the DS, especially at a high $\mathrm{NaOH}$ amount. ${ }^{13}$

Table 1 Measured DS of CMPSs

\begin{tabular}{lccc}
\hline Sample & MCA/AGU & NaOH/MCA & DS \\
\hline CMPS-1 & 3.0 & 2.4 & 0.96 \\
CMPS-2 & 3.0 & 2.2 & 1.24 \\
CMPS-3 & 3.0 & 2.0 & 0.79 \\
CMPS-4 & 3.0 & 1.8 & 0.63 \\
CMPS-5 & 2.5 & 2.4 & 0.73 \\
CMPS-6 & 2.5 & 2.2 & 1.06 \\
CMPS-7 & 2.5 & 2.0 & 0.90 \\
CMPS-8 & 2.5 & 1.8 & 0.86 \\
CMPS-9 & 2.0 & 2.4 & 0.70 \\
CMPS-10 & 2.0 & 2.2 & 1.04 \\
CMPS-11 & 2.0 & 2.0 & 0.82 \\
CMPS-12 & 2.0 & 1.8 & 0.63 \\
CMPS-13 & 1.5 & 2.4 & 0.86 \\
CMPS-14 & 1.5 & 2.2 & 0.88 \\
CMPS-15 & 1.5 & 2.0 & 0.68 \\
CMPS-16 & 1.5 & 1.8 & 0.59 \\
CMPS-17 & 1.0 & 2.4 & 0.63 \\
CMPS-18 & 1.0 & 2.2 & 0.72 \\
CMPS-19 & 1.0 & 2.0 & 0.67 \\
CMPS-20 & 1.0 & 1.8 & 0.51 \\
CMPS-21 & 0.9 & 2.2 & 0.69 \\
CMPS-22 & 0.8 & 2.2 & 0.65 \\
CMPS-23 & 0.7 & 2.2 & 0.57 \\
CMPS-24 & 0.6 & 2.2 & 0.49 \\
CMPS-25 & 0.5 & 2.2 & 0.39 \\
CMPS-26 & 0.4 & 2.2 & 0.25 \\
CMPS-27 & 0.3 & 2.2 & 0.14 \\
CMPS-28 & 0.2 & 2.2 & 0.11 \\
CMPS-29 & 0.1 & 2.2 & 0.04 \\
\hline
\end{tabular}



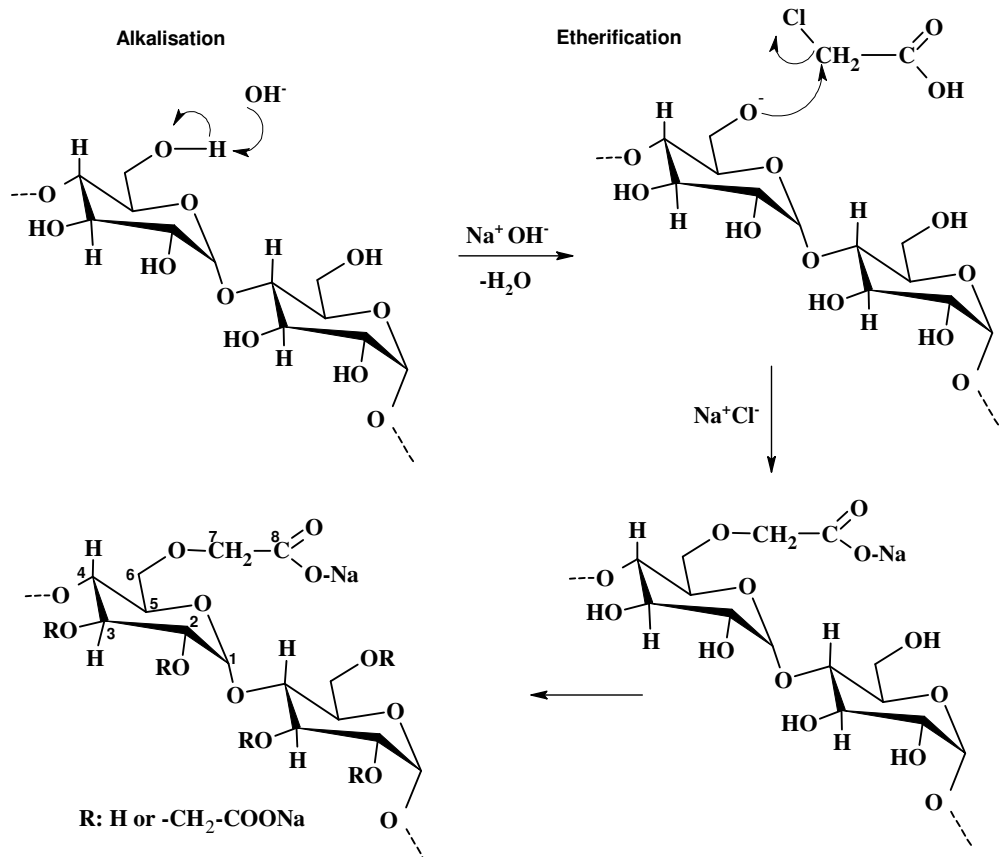

Figure 1: Synthesis of CMPS

Table 2

Measured viscosity of CMPSs

\begin{tabular}{lc}
\hline Sample & $\begin{array}{c}\text { Viscosity of } 2 \mathrm{wt} \% \\
\text { CMPS (mPas) }\end{array}$ \\
\hline CMPS-2 & 14200 \\
CMPS-6 & 9900 \\
CMPS-10 & 9500 \\
CMPS-14 & 8200 \\
CMPS-18 & 7200 \\
CMPS-21 & 5000 \\
CMPS-22 & 3400 \\
CMPS-23 & 2300 \\
CMPS-24 & 1200 \\
CMPS-25 & 700 \\
CMPS-26 & 100 \\
CMPS-27 & 80 \\
CMPS-28 & 50 \\
CMPS-29 & 20 \\
\hline iscosity measurement was obtained at $1 \mathrm{rpm}$
\end{tabular}

Effect of various molar ratios of $\mathrm{NaOH}$ to starch

The influence of various molar $\mathrm{NaOH}: \mathrm{MCA}$ ratios on the DS is shown in Figure 2. The molar ratios of $\mathrm{NaOH}$ to the anhyroglycose unit (AGU) were varied from 2.2 to 6.6 , while the other reaction conditions were kept constant $\left(45^{\circ} \mathrm{C}\right.$ for $180 \mathrm{~min})$. The increase in the molar ratio of $\mathrm{NaOH}: \mathrm{MCA}$ increased the DS until it reached 6.6 and a maximum DS of 1.24 was recorded. Figure 2 shows the DS ranging between 0.04 and 1.24. The DS of the CMPSs increased and reached the maximum DS of 1.24 at the $\mathrm{NaOH} / \mathrm{AGU}$ molar ratio of 2.2. During the carboxymethylation process, the $\mathrm{NaOH}$ provides the alkaline environment for the reaction while also serving as swelling agent to facilitate diffusion and penetration of the etherifying agent to the granular 
structure of the starch. ${ }^{45}$ However, the starch then began to gelatinize and the contact between MCA and the starch was inhibited by the further increase in the $\mathrm{NaOH}$ amount. Moreover, further increase in the $\mathrm{NaOH}$ concentration diverted the side reaction of MCA. These observations could explain the reduction in the DS at higher $\mathrm{NaOH} / \mathrm{MC}$ ratios. $^{45}$

Table 3

Results for unsized and sized yarns with WPS, CMPS-29 (DS = 0.04), CMPS-27 (DS = 0.14), CMPS-25

$(\mathrm{DS}=0.39)$ and CMPS-22 $(\mathrm{DS}=0.65)$

\begin{tabular}{cccc}
\hline $\begin{array}{c}\text { Yarn number } \\
(\mathrm{Ne})\end{array}$ & Sample & $\begin{array}{c}\text { Tensile strength } \\
(\mathrm{cN} / \text { tex })\end{array}$ & $\begin{array}{c}\text { Elongation at break } \\
(\%)\end{array}$ \\
\hline \multirow{4}{*}{$10 / 1$} & Unsized & 14.90 & 10.41 \\
& WPS & 26.41 & 12.37 \\
& CMPS-29 & 27.96 & 13.23 \\
& CMPS-27 & 27.72 & 12.27 \\
& CMPS-25 & 23.78 & 10.20 \\
& CMPS-22 & 23.43 & 13.48 \\
& Unsized & 10.80 & 6.99 \\
& WPS & 15.71 & 8.04 \\
& CMPS-29 & 16.88 & 7.71 \\
& CMPS-27 & 16.51 & 6.26 \\
& CMPS-25 & 16.19 & 6.10 \\
& CMPS-22 & 14.18 & 8.85 \\
& Unsized & 14.83 & 5.14 \\
& WPS & 21.13 & 8.14 \\
& CMPS-29 & 23.25 & 7.72 \\
& CMPS-27 & 22.42 & 7.54 \\
& CMPS-25 & 20.35 & 7.09 \\
& CMPS-22 & 20.17 & 6.27 \\
\hline
\end{tabular}

\section{Effect of various molar ratios of MCA to starch}

The results obtained by investigating the influence of the ratio of MCA to starch on the values of DS are presented in Figure 2. The reaction conditions during these experiments of the carboxymethylation of WPS were constant $\left(45^{\circ} \mathrm{C}\right.$ for $\left.180 \mathrm{~min}, \mathrm{NaOH}: \mathrm{MCA}=2.2\right)$, but the molar ratio of MCA to AGU was varied from 0.1 to 3. Figure 2 shows CMPSs with varying DS. The DS values of CMPSs increased linearly with increasing MCA content in the reaction mixture. The increasing MCA/AGU ratio could lead to the usage of $\mathrm{NaOH}$, so less $\mathrm{NaOH}$ can react with AGU, so higher MCA/AGU ratio leads to a lower DS. Also, this leads to sodium glycolate side reactions.

\section{Viscosity of CMPS aqueous solutions}

The water solubility of CMPS is a complex phenomenon and depends on the degree of substitution and the temperature of the environment. The sodium carboxylate form of CMPS is soluble in water. ${ }^{46}$ Generally, CMPSs with a high degree of substitution have high solubility in cold water. ${ }^{47}$ Highly substituted
CMPS has higher viscosity than the low substituted one. ${ }^{48}$ The electrostatic effect between polysaccharide chains with a high DS increases the viscosity by further widening the molecules. ${ }^{47}$ It is also known that the viscosity of the polysaccharides depends on the molecular weight. ${ }^{13}$ As the carboxymethyl derivatives of starch are synthesized, the temperature and the heavy alkaline conditions of the environment lead to the degradation of the carbohydrate molecules, resulting in variants with different viscosities and DS values. This situation also varies according to the starch source. ${ }^{40}$

In Figure 3, the influence of MCA content on the DS values and viscosity of the $2 \mathrm{wt} \%$ CMPS aqueous solution is presented. Significantly higher viscosity values can be observed in a low range of shear force $(<10 \mathrm{rpm}){ }^{40,46}$ The viscosity of the $2 \mathrm{wt} \%$ CMPS aqueous solutions ranged between $20-14200 \mathrm{mPa} \cdot \mathrm{s}$ and $25-1142$ at $1 \mathrm{rpm}$ and $100 \mathrm{rpm}$, respectively. It can be noted that the viscosity of the prepared CMPSs increased gradually with the increase in the DS values. The viscosity increased with upon the incorporation of carboxymethyl groups in the starch molecules. ${ }^{11,13}$ When the hydroxyl groups are substituted by 
carboxymethyl groups, the molecular weight of the starch increases, and as a result, the viscosity of CMPSs increases.

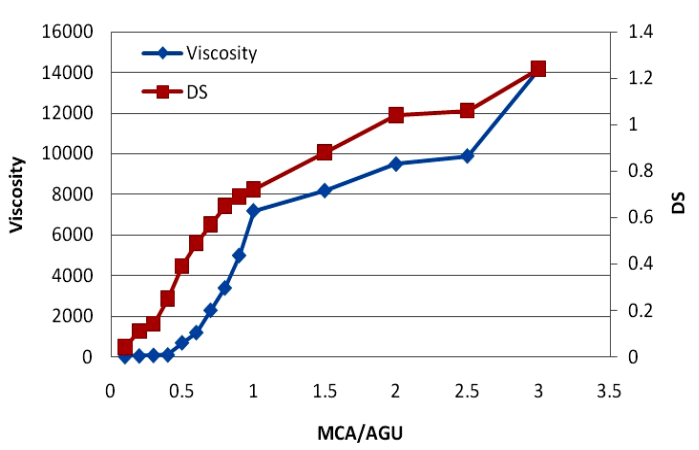

Figure 3: Influence of MCA to starch ratio (AGU) on DS and viscosity of CMPSs

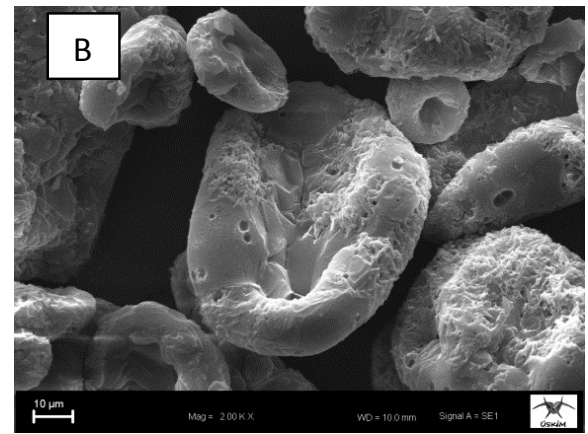

Figure 4: SEM micrographs of WPS (A) and CMPS-2 (DS = 1.24) (B)

\section{Granule morphology}

The morphology of WPS and carboxymethylated starch granules was examined by a scanning electron microscope (JEAL/NEOSCOPE JCM-5000 SEM). The SEM micrographs of waste potato starch and CMPSs are shown in Figure 4. A smooth surface was observed for the elliptically shaped WPS granules. Comparing with waste potato starch, the granules of CMPSs had indented surfaces and some areas on the granule surface became shrunken and even fractured. After carboxymethylation, the granular shape was altered because of the alkaline conditions. ${ }^{13,18,40}$ Strong alkaline conditions affected the changes on the starch granules, so the granules lost their crystalline structure. It is possible that carboxymethylation took place both on the surface and inside the starch granules. These findings prove the modification of starch. This result is in good agreement with those reported in the literature. ${ }^{13,18,40}$

\section{FT-IR spectroscopy}

WPS, bleached WPS and carboxymethyl potato starch were characterized by Fourier transform infrared (FT-IR) spectroscopy (Perkin Elmer Spectrum 400). The FT-IR spectra of WPS and bleached WPS are closely similar to each other. The $\mathrm{H}_{2} \mathrm{O}_{2}$, which is a weak acid, did not cause a considerable change in the FT-IR spectrum. Some differences in relation to the functional groups in the carboxymethyl potato starch and the waste potato starch were detected on the FT-IR spectra presented in Figure 5. The broad band around $3273 \mathrm{~cm}^{-1}$ assigned to the hydrogen bond corresponds to the hydroxyl groups on the starch molecules. The band at 2920 $\mathrm{cm}^{-1}$ is assigned to the symmetrical stretching vibrations of $-\mathrm{CH}_{2}$.

When comparing the spectra of the CMPSs and WPS molecules, the vibrational band observed at $1642 \mathrm{~cm}^{-1}$ in the spectrum of the waste potato starch disappeared in the spectra of the carboxymethyl potato starch. New peaks 
occurred corresponding to the specific groups after the etherification reaction, which indicated the substitution of carboxylic groups. These strong absorption bands assigned to the asymmetric and symmetric vibration of $-\mathrm{COO}^{-}$are located at 1586 and $1415 \mathrm{~cm}^{-1}$, respectively. These bands confirm the carboxymethylation of the starch molecules. ${ }^{18,49}$ Table 4 shows the major FTIR peaks of the CMPS samples and WPS.

\section{XRD analysis}

The crystalline characteristics of the samples were investigated by the X-ray diffraction method (XRD) (Philips X'Pert PRO). Diffraction patterns of waste potato starch, CMPS-26 ( $\mathrm{DS}=0.25)$,
CMPS-14 (DS = 0.88) and CMPS-6 (1.06) are shown in Figure 6. The diffractogram of WPS exhibits a typical B-type crystallinity pattern. ${ }^{50} \mathrm{It}$ can be observed that while the structure of waste potato was semi-crystalline, the crystallinity disappeared after the etherification reaction (e.g. DS $=0.25$ and 0.88 ). The loss of crystallinity could be due to the effect of the alkaline environment during the modification. ${ }^{27,43}$ The breakage of chemical bonds in the starch granules upon the heat treatment was also a possible reason of the loss of crystallinity. ${ }^{50}$ On the other hand, when the DS value increased from 0.25 to 1.06 , the structure turned again into a crystal one, with a typical B-type crystallinity pattern.

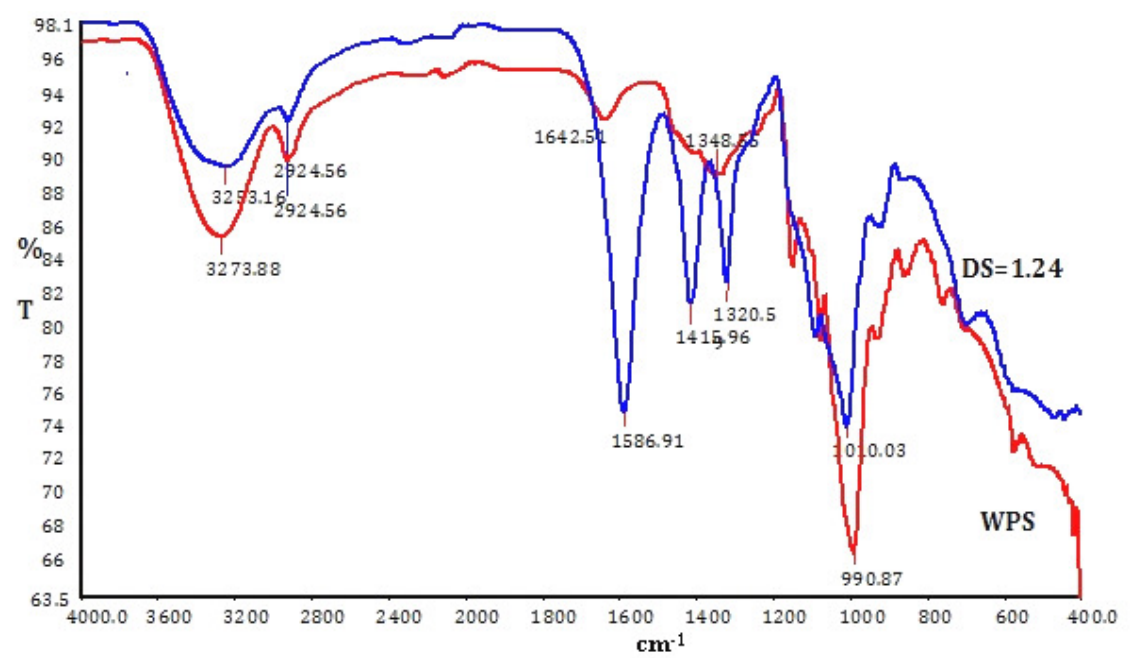

Figure 5: FT-IR spectra of WPS and CMPS-2 (DS = 1.24)

Table 4

Major FTIR peaks of WPS and CMPS samples

\begin{tabular}{lccc}
\hline Sample & $v(\mathrm{OH})$ & $v\left(\mathrm{CH}_{2}\right)$ & $v\left(\mathrm{COO}^{-}\right)$ \\
\hline WPS & 3234 & 2923 & - \\
WPS & 3273 & 2920 & - \\
CMPS-2 & 3275 & 2916 & $1586-1415$ \\
CMPS-6 & 3272 & 2901 & $1594-1417$ \\
CMPS-10 & 3252 & 2912 & $1587-1415$ \\
CMPS-14 & 3212 & 2916 & $1587-1411$ \\
CMPS-18 & 3230 & 2916 & $1586-1415$ \\
CMPS-21 & 3222 & 2912 & $1587-1411$ \\
CMPS-22 & 3230 & 2909 & $1589-1411$ \\
CMPS-23 & 3252 & 2916 & $1589-1411$ \\
CMPS-24 & 3274 & 2909 & $1591-1411$ \\
CMPS-25 & 3262 & 2920 & $1591-1416$ \\
CMPS-26 & 3249 & 2920 & $1590-1411$ \\
CMPS-27 & 3252 & 2924 & $1591-1416$ \\
CMPS-28 & 3274 & 2916 & $1591-1332$ \\
CMPS-29 & 3273 & 2920 & $1590-1334$ \\
\hline
\end{tabular}

WPS bleached by $\mathrm{H}_{2} \mathrm{O}_{2}$ 


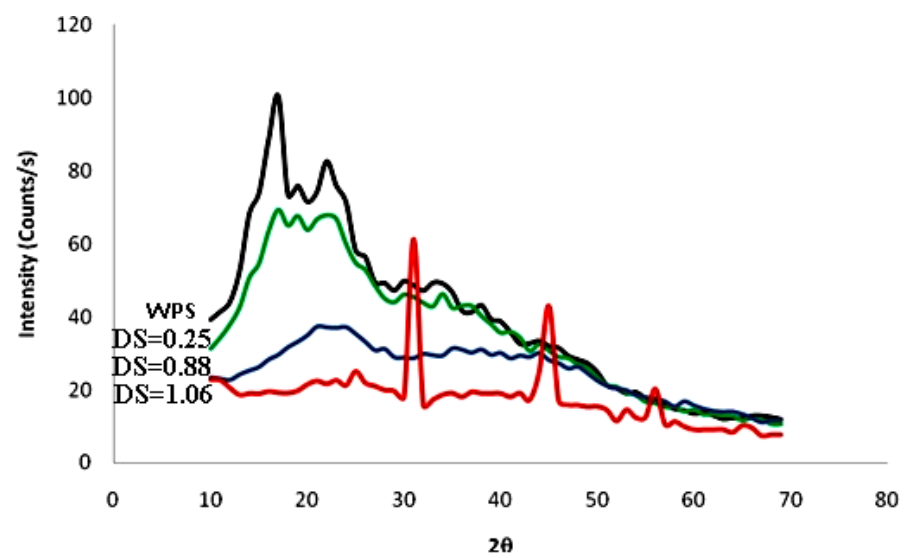

Figure 6: XRD patterns of WPS and CMPSs $(\mathrm{DS}=0.25, \mathrm{DS}=0.88$ and DS $=1.06$ )

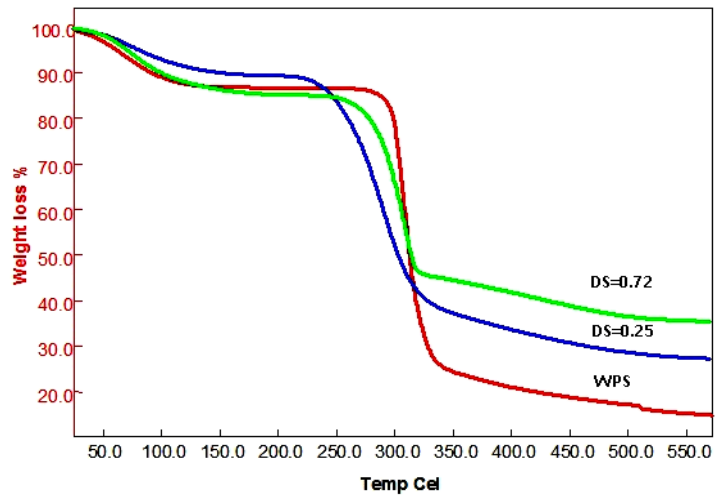

Figure 7: Weight loss for WPS and CMPSs (DS $=0.25$ and DS $=0.72$ )

\section{Thermal properties}

DTG measurements were performed by a SEIKO II TG-DTA. The polymeric materials were evaluated by thermogravimetric analysis to determine their thermal stability. The DTG and TG curves for the WPS and CMPSs are presented in Figures 7 and 8. According to the TG curves, the CMPSs start decomposing at a lower temperature than the WPS. As seen in Figure 7, the weight loss in the temperature range from 50 to $120{ }^{\circ} \mathrm{C}$, which is the first step of degradation, was related to moisture (or free water) evaporation, while the second one corresponded to decomposition. ${ }^{51}$ Comparing with WPS, which decomposed at $300{ }^{\circ} \mathrm{C}$, the decomposition of CMPSs (DS $=0.25$ and 0.88 ) started at 200 and $250{ }^{\circ} \mathrm{C}$, respectively. The waste potato starch showed the fastest rate of decomposition as the temperature increased. On the contrary, the CMPSs with the DS values of $0.25,0.88$ and 1.06 exhibited lesser weight loss (Fig. 8). The residual

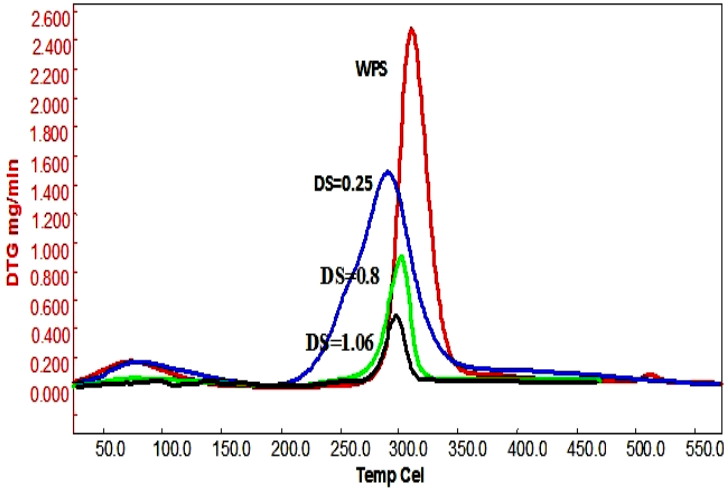

Figure 8: DTG curves for WPS and CMPSs (DS = $0.25, \mathrm{DS}=0.88$ and $\mathrm{DS}=1.06$ )

mass of CMPS could be higher than that of the waste potato starch due to the inorganic components produced during
carboxymethylation. ${ }^{43,52}$

\section{${ }^{1} \mathbf{H}\left({ }^{13} \mathrm{C}\right)$-NMR analysis}

${ }^{1} \mathrm{H}$-NMR spectroscopy of CMPS was carried out in $\mathrm{D}_{2} \mathrm{O}$. The spectrum obtained for CMPS (DS $=0.88$ ) and the signal assignment is shown in Figure 9. It was noted that the CMPS produced signals in the region of $5.28-5.33 \mathrm{ppm}$. The signals in the region of 4.64-4.67 ppm were assigned to the protons bound to the 2, 3, 6 positions of the AGU; the signals in the region of 3.73-3.85 ppm were assigned to the basic chemical shifts of the protons at carbon 6,2, 3 of the glucose unit; and the signals in the region of 3.24-3.53 ppm could be chemical shifts of the proton at carbon 5 and 4 of the glucose unit, respectively. ${ }^{23,53}$ 


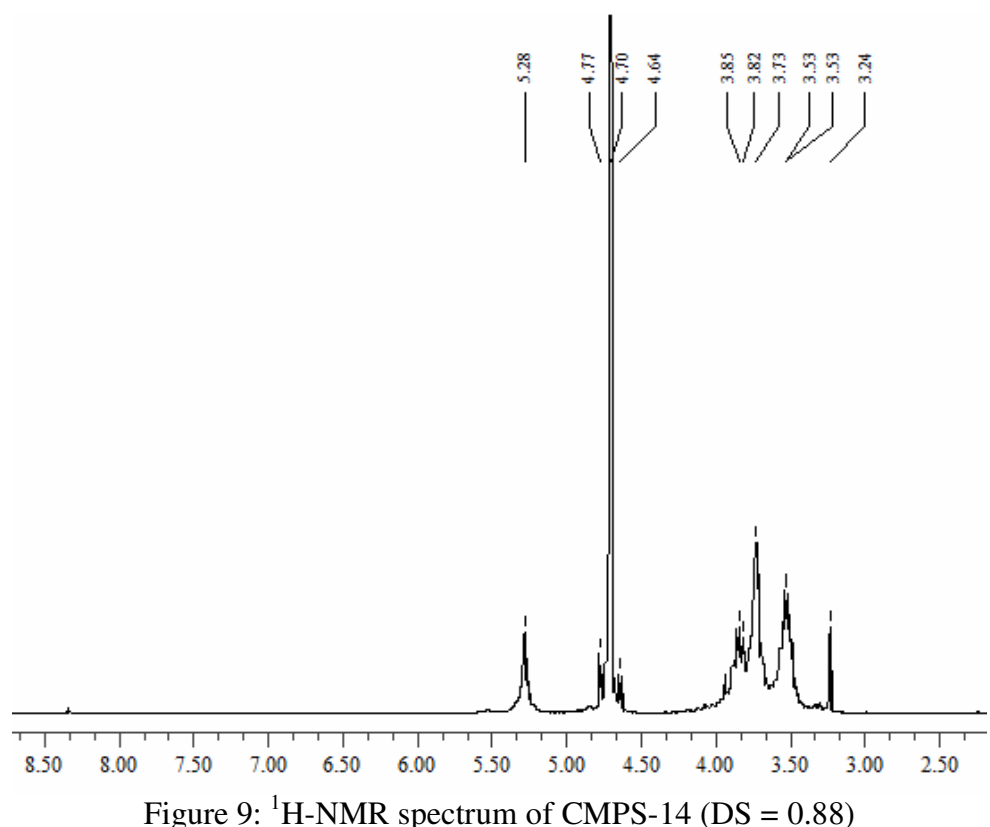

Figure 9: ${ }^{1} \mathrm{H}-\mathrm{NMR}$ spectrum of CMPS-14 (DS $\left.=0.88\right)$
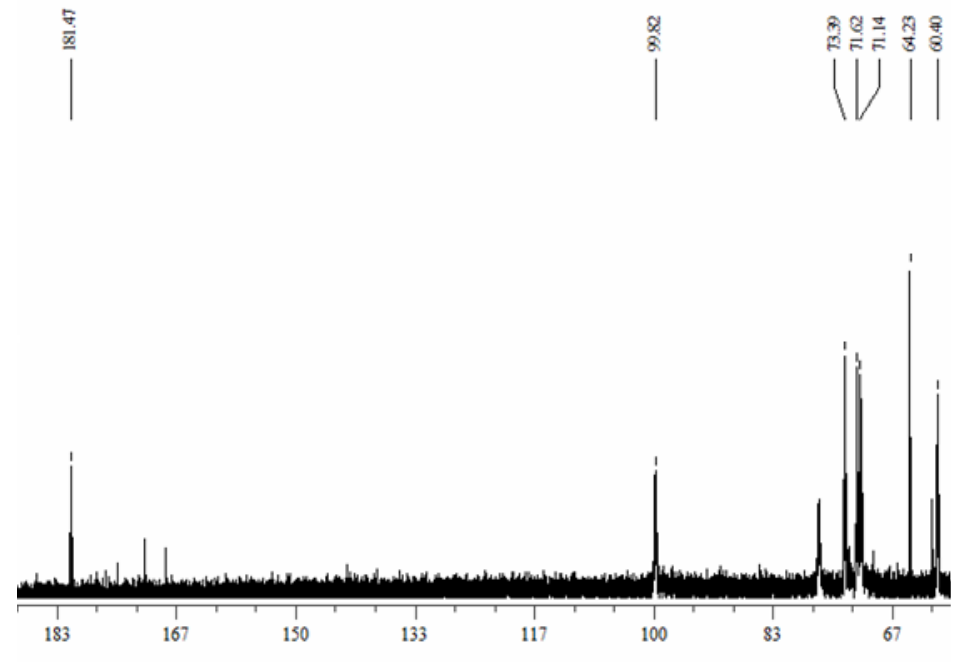

ppm

Figure 10: ${ }^{13} \mathrm{C}-\mathrm{NMR}$ spectrum of CMPS-14 (DS $\left.=0.88\right)$

The samples of CMPS were dissolved in $\mathrm{D}_{2} \mathrm{O}$ (Fig. 10). Signals of $-\mathrm{COOH}(\mathrm{C}-8)$ appeared at $180.47 \mathrm{ppm}$. This peak is associated with carboxymethylation. The signals of C-1 and C-4 appear at 99.82 and $76.99 \mathrm{ppm}$, respectively. The C-4 peak is attributed to the presence or absence of the carboxymethyl substituent on C-3. The peak at $73.39 \mathrm{ppm}$ is assigned to C-2. Signals of C-3 and C-5 are detected at 71.62 and 71.14 ppm, respectively. The absorption peak at $60.40 \mathrm{ppm}$ is assigned to C-6, while that at $64.23 \mathrm{ppm}$ corresponds to $\mathrm{C}-7.32,54,55$

\section{Sizing of cotton yarns}

Starch and its derivatives are among the sizing agents that are widely used in sizing of cottonbased textiles. ${ }^{56}$ Different substituted CMPSs (DS $=0.04-1.24)$ were synthesized from waste potato starch (WPS). The sizability of WPS and CMPSs with low DS values (0.04-0.65) was assessed by 
monitoring the tensile strength and elongation at break (Fig. 11). As seen in Table 4, the tensile strength of the $100 \%$ cotton yarns increases as a result of CMPS sizing. Moreover, the tensile strength of the cotton yarn sized with CMPS-29 $(\mathrm{DS}=0.04)$ showed a higher value than in the case of WPS. Also, the tensile strength of the cotton yarn sized (30/1 Ne) with WPS and CMPS-29 was 21.13 and $23.25 \mathrm{cN} / \mathrm{tex}$, respectively. Otherwise said, the percentage of the increase in the tensile strength was $14.30 \%$.
Compared with waste potato starch, as the DS value of CMPSs decreased until 0.04, they exhibited much better sizing performance. On the other hand, the tensile strength of the unsized cotton yarn (10/1 Ne) and CMPS-29 was 14.90 and $27.96 \mathrm{cN} / \mathrm{tex}$, respectively. The sizing efficiency of CMPS-29 of $87.65 \%$ evidences the suitability of the CMPS under study to be used as a sizing agent. Also, it can be observed that the CMPS with DS 0.04 had considerably better sizing properties compared to the WPS sample.

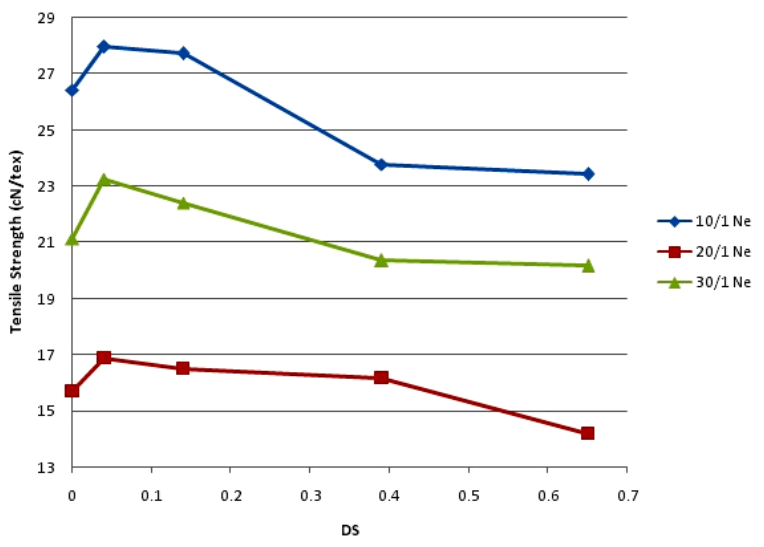

Figure 11: Tensile strength of sized cotton yarns

The results in Table 3 indicate that the cotton yarns of 10/1 Ne and 20/1 Ne, which were sized with CMPS-22 (DS = 0.65) and CMPS-29 (DS = 0.04), exhibited an increase in elongation at break, relative to that sized with WPS, and a slight change or decrease for CMPS-27 (DS = 0.14) and CMPS-25 (DS = 0.39). Also, the elongation at break for the cotton yarn (10/1 Ne) sized with WPS and CMPS-22 was 12.37 and 13.48, respectively. On the other hand, the elongation at break values for the cotton yarns $(30 / 1 \mathrm{Ne})$ sized with WPS and CMPSs are almost equal.

\section{CONCLUSION}

CMPSs were synthesized for the first time from waste potato starch, obtained from a chips factory, under heterogeneous conditions, as products of the reaction of WPS and MCA in the presence of $\mathrm{NaOH}$. Considering all the studied conditions, it was established that the best results were achieved using IPA as a solvent at $45{ }^{\circ} \mathrm{C}$ for $180 \mathrm{~min}$ and a $\mathrm{NaOH} / \mathrm{MCA}$ molar ratio of $2.2: 1$. Under these conditions, the obtained CMPS-2 showed a viscosity of 14200 $\mathrm{mPa}$ s (for $2 \% \mathrm{CMPS}$ in water at $1 \mathrm{rpm}$ ) at the highest DS. The $100 \%$ cotton yarns were sized using CMPS-29, CMPS-27, CMPS-25 and CMPS-22. It was noted that as the DS values of the CMPS decreased, the sizing efficiency increased. The sizing efficiency of CMPS-29 of $87.65 \%$ evidenced its suitability to be used as a sizing agent. Additionally, it can be observed that the CMPS with DS 0.04 had considerably better sizing properties compared to WPS.

ACKNOWLEDGEMENT: This work was supported by Kahramanmaras Sutcu Imam University Scientific Research Project (BAP Project Number: 2014/3-12 YLS).

\section{REFERENCES}

1 I. Vroman and L. Tighzert, Materials, 2, 307 (2009), https://doi.org/10.3390/ma2020307

2 H. Angellier, L. Choisnard, S. Molina-Boisseau, P. Dole and A. Dufresne, Biomacromolecules, 5, 1545 (2004), DOI: 10.1021/bm049914u

3 Z. Stojanovic, K. Jeremic and S. Jovanovic, Starch/Stärke, $\quad 52, \quad 413 \quad$ (2000), https://doi.org/10.1002/1521-

379X(200011)52:11<413::AID-STAR413>3.0.CO;2-B 
4 N. Nagasawa, T. Yagi, T. Kume and F. Yoshii, Carbohyd. Polym., 58, $109 \quad$ (2004), https://doi.org/10.1016/j.carbpol.2004.04.021

5 P. Chatakanonda, S. Varavinit and P. Chinachoti, LWT-Food Sci. Technol., 33, $276 \quad$ (2000), https://doi.org/10.1006/fstl.2000.0662

6 P. Tolvanen, P. Maki-Arvela, A. B. Sorokin, T. Salmi and D. Y. Murzin, Chem. Eng. J., 154, 52 (2009), DOI: 10.1016/j.cej.2009.02.001

7 H. S. Kim, H. S. Choi, B. Y. Kim and M. Y. Baik, Carbohyd. Polym., 83, $755 \quad$ (2011), https://doi.org/10.1016/j.carbpol.2010.08.048

8 A. Gunaratne and H. Corke, Carbohyd. Polym., 68, 305

(2007),

https://doi.org/10.1016/j.carbpol.2006.12.004

9 S. Mishra, A. Mukul, G. Sen and U. Jha, Int. J. Biol. Macromol., 48, 106 (2011), doi: 10.1016/j.ijbiomac.2010.10.004

10 T. S. Anirudhan and J. Parvathy, Int. J. Biol. Macromol., $\quad$ 67, $238 \quad$ (2014), $\quad$ doi: 10.1016/j.ijbiomac.2014.03.041

11 S. E. Barrios, J. M. Contreras, F. LopezCarrasquero and A. J. Müller, Revista de la Facultad de Ingenieria U.C.V., 27, 97 (2012).

12 H. Y. Qiu and L. M. He, Polym. Adv. Technol., 10, 468 (1999), https://doi.org/10.1002/(SICI)10991581(199907)10:7<468::AID-PAT898>3.0.CO;2-W

13 K. Sangseethong, S. Ketsilp and K. Sriroth, $\begin{array}{lll}\text { Starch/Stärke, } & 57, & 84\end{array}$ https://doi.org/10.1002/star.200400302

14 D. Bhattacharyya, R. S. Singhal and P. R. Kulkarni, Carbohyd. Polym., 3, $167 \quad$ (1995), https://doi.org/10.1016/0144-8617(95)00062-C

15 T. Nabais, F. Brouillet, S. Kyriacos, M. Mroueh, P. Amores da Silva et al., Eur. J. Pharm. Biopharm., 65, 371 (2007), https://doi.org/10.1016/j.ejpb.2006.12.001

16 C. J. Tijsen, H. J. Kolk, E. J. Stamhuis and A. A. C. M. Beenackers, Carbohyd. Polym., 3, 219 (2001), https://doi.org/10.1016/S0144-8617(00)00243-5

17 P. N. Bhandari and M. A. Hanna, Starch/Stärke, 63, 771 (2011), https://doi.org/10.1002/star.201100035 18 Y. Bi, M. Liu, L. Wu and D. Cui, Polym. Adv. Technol., $\quad 19, \quad 1185 \quad$ (2008), https://doi.org/10.1002/pat.1102

19 B. Zhang, H. Gong, S. Lü, B. Ni, M. Liu et al., Int. J. Biol. Macromol., 51, 668 (2012), https://doi.org/10.1016/j.ijbiomac.2012.07.003

20 Z. W. Wu and X. Y. Song, J. Appl. Polym. Sci., 101, 2210 (2006), https://doi.org/10.1002/app.23479

${ }^{21}$ K. Kwon, J. H. Auh, J. W. Kim, K. H. Park and C. H. Park, Starch/ Stärke, 49, 499 (1997), https://doi.org/10.1002/star.19970491207

22 W. Lazik, T. Heinze, K. Pfeiffer, G. Albrecht and P. Mischnick, J. Appl. Polym. Sci., 86, 743 (2002), https://doi.org/10.1002/app.10983

23 T. Heinze and A. Koschella, Macromol. Symp., 223, $13 \quad$ (2005), https://doi.org/10.1002/masy.200550502
24 S. Mohapatra, M. Asfer, M. Anwar, S. Ahmed, F. Ahmad et al., Int. J. Biol. Macromol., 115, 920 (2018), doi: 10.1016/j.ijbiomac.2018.04.152

25 P. Rachtanapun, P. Simasatitkul, W. Chaiwan and Y. Watthanaworasakun, Int. Food Res. J., 19, 923 (2012)

26 O. S. Kittipongpatana, J. Sirithunyalug and R. Laenger, Carbohyd. Polym., 1, 105 (2006), doi: 10.1016/j.carbpol.2005.08.024

27 W. Yanli, G. Wenyuan and L. Xia, Carbohyd. Res., 13, 1764 (2009), doi: 10.1016/j.carres.2009.06.014

28 D. K. Raval, S. P. Patel, R. G. Patel and V. S. Patel, Starch/ Stärke, 10, $399 \quad$ (1994), https://doi.org/10.1002/star.19940461008

29 D. Bhattacharyya, R. S. Singhal and P. R. Kulkarni, Carbohyd. Polym., 4, 247 (1995), doi: 10.1016/0144-8617(95)00083-6.

30 P. M. Ganorkar and A. S. Kulkarni, Int. Food Res. J., 20, 2205 (2013), https://pdfs.semanticscholar.org/e003/833f334c31f82a 9737a26a1b553dcc585319.pdf

31 L. M. Kooijman, K. J. Ganzeveld, R. M. Manurung and H. J. Heeres, Starch/Stärke, 55, 495 (2003), https://doi.org/10.1002/star.200300217

32 O. S. Lawal, M. D. Lechner and W. M. Kulicke, Int. J. Biol. Macromol., 42, 429 (2008).

33 G. K. Bolhuis, K. Zuurman and G. H. P. Te Wierik, Eur. J. Pharm. Biopharm., 5, 63 (1997).

34 N. Huyghebaert, V. Snoeck, A. Vermeire, E. Cox, B. M. Goddeeris et al., Eur. J. Pharm. Biopharm., 59, 273 (2005).

35 E. Csiszar, J. Borsa and S. K. Obendorf, Arch. Environ. Contam. Toxicol., 35, 129 (1998).

36 E. P. A. Kumbasar and M. Bide, Dyes Pigments., 47, 189 (2000).

37 K. M. Mostafa and M. S. Morsy, Starch/Stärke, 56, 189 (2004).

38 A. A. Ragheb, H. S. El-Sayiad and A. Hebeish, Starch/Stärke, 49, 238 (1997).

39 B. S. Kim and S. T. Lim, Carbohyd. Polym., 39, 217 (1999).

40 T. Spychaj, M. Zdanowicz, J. Kujawa and B. Schmidt, Polimery (Warsaw), 7-8, 503 (2013).

41 Z. Luo and Z. Xu, LWT - Food Sci. Technol., 44, 1993 (2011)

${ }^{42}$ F. Cheng, J. W. Betts, S. M. Kelly, D. W. Wareham, A. Kornherr et al., J. Mater. Chem. B., 2, 3057 (2014).

43 T. Spychaj, K. Wilpiszewska and M. Zdanowicz, Starch/Stärke, $\quad \mathbf{6 5}, \quad 22 \quad$ (2013), https://doi.org/10.1002/star.201200159

44 V. H. Kessel, Starch, 37, 334 (1985).

45 J. Liu, J. Ming, W. Li and G. Zhao, Food Chem., 133, $1196 \quad$ (2012), https://doi.org/10.1016/j.foodchem.2011.05.061

${ }^{46}$ Z. P. Stojanovic, K. Jeremic, S. Jovanovic, W. Nierling and M. D. Lechner, Starch/Stärke, 61, 199 (2009), https://doi.org/10.1002/star.200800085 
47 J. Tatongjai and N. Lumdubwong, Carbohyd. Polym., 81, 377 (2010), https://doi.org/10.1016/j.carbpol.2010.02.019

48 S. Li, J. M. V. Mujyambere and M. Liu, $A d v$. Mater. Res., 233, $306 \quad$ (2011), https://doi.org/10.4028/www.scientific.net/AMR.233235.306

49 X. Li, W. Gao, L. Huang, Y. Wang, L. Huang et al., Carbohyd. Polym., 80, 768 (2010), https://doi.org/10.1016/j.carbpol.2009.12.025

50 X. D. Zhang, X. Liu and W. Y. Li, J. Appl. Polym. $\begin{array}{llll}\text { Sci., } & \mathbf{8 9}, & 3016 & \end{array}$ https://doi.org/10.1002/app.12438

51 K. Wilpiszewska, M. Zdanowicz and T. Spychaj, Adv. Polym. Technol., 32, $21353 \quad$ (2013), https://doi.org/10.1002/adv.21353
52 D. Binh, P. T. T. H. Hong, N. N. Duy, N. T. Duoc and N. N. Dieu, Radiat. Phys. Chem., 81, 906 (2012), https://doi.org/10.1016/j.radphyschem.2011.12.016

53 W. Gao, X. Lin, X. Lin, J. Ding, X. Huang et al., Carbohyd. Polym., 84, $1413 \quad$ (2011), https://doi.org/10.1016/j.carbpol.2011.01.056

54 L. F. Wang, S. Y. Pan, H. Hu, W. H. Miao and X. Y. Xu, Carbohyd. Polym., 80, 174 (2010), 10.1016/j.carbpol.2009.11.008

55 A. Hebeish, A. Higazy, A. El-Shafei and S. Sharaf,

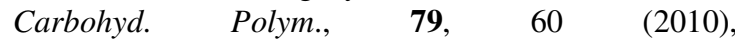
https://doi.org/10.1016/j.carbpol.2009.07.022 